\title{
Continuous flow analysis methods for sodium, magnesium and calcium detection in the Skytrain ice core
}

\section{Article}

Cite this article: Grieman MM, Hoffmann HM, Humby JD, Mulvaney R, Nehrbass-Ahles C, Rix J, Thomas ER, Tuckwell R, Wolff EW (2022). Continuous flow analysis methods for sodium, magnesium and calcium detection in the Skytrain ice core. Journal of Glaciology 68(267), 90-100. https://doi.org/10.1017/jog.2021.75

Received: 31 August 2020

Revised: 4 June 2021

Accepted: 7 June 2021

First published online: 9 July 2021

\section{Key words:}

Glaciological instruments and methods; ice core; paleoclimate

\section{Author for correspondence:}

Mackenzie M. Grieman,

E-mail:mmg46@cam.ac.uk (c) The Author(s), 2021. Published by Cambridge University Press. This is an Open Access article, distributed under the terms of the Creative Commons Attribution licence (http://creativecommons.org/licenses/by/4.0/), which permits unrestricted re-use, distribution, and reproduction in any medium, provided the original work is properly cited.

\author{
Mackenzie M. Grieman ${ }^{1}$ (D), Helene M. Hoffmann ${ }^{1}$, Jack D. Humby ${ }^{2}$ (D), \\ Robert Mulvaney ${ }^{2}$ (D), Christoph Nehrbass-Ahles ${ }^{1}$ (D), Julius Rix ${ }^{2}$ (D), \\ Elizabeth R. Thomas ${ }^{2}$ (D), Rebecca Tuckwell ${ }^{2}$ (D) and Eric W. Wolff ${ }^{1}$ (i)
}

${ }^{1}$ Department of Earth Sciences, University of Cambridge, Cambridge, UK and ${ }^{2}$ British Antarctic Survey, Cambridge, UK

\begin{abstract}
Dissolved and particulate sodium, magnesium and calcium are analyzed in ice cores to determine past changes in sea ice extent, terrestrial dust variability and atmospheric aerosol transport efficiency. They are also used to date ice cores if annual layers are visible. Multiple methods have been developed to analyze these important compounds in ice cores. Continuous flow analysis (CFA) is implemented with instruments that sample the meltstream continuously. In this study, CFA with ICP-MS (inductively coupled-plasma mass spectrometry) and fast ion chromatography (FIC) methods are compared for analysis of sodium and magnesium. ICP-MS, FIC and fluorescence methods are compared for analysis of calcium. Respective analysis of a $10 \mathrm{~m}$ section of the Antarctic WACSWAIN Skytrain Ice Rise ice core shows that all of the methods result in similar levels of the compounds. The ICP-MS method is the most suitable for analysis of the Skytrain ice core due to its superior precision (relative standard deviation: $1.6 \%$ for $\mathrm{Na}, 1.3 \%$ for $\mathrm{Mg}$ and $1.2 \%$ for $\mathrm{Ca}$ ) and sampling frequency compared to the FIC method. The fluorescence detection method may be preferred for calcium analysis due to its higher depth resolution $(1.4 \mathrm{~cm})$ relative to the ICP-MS and FIC methods $(\sim 4 \mathrm{~cm})$.
\end{abstract}

\section{Introduction}

The chemical content of ice cores has been extensively used as a proxy for environmental change. Comparison between various ions and elements preserved in ice cores is a valuable tool for delineating changes in past marine and terrestrial conditions. The aim of the WArm Climate Stability of the West Antarctic ice sheet in the last INterglacial (WACSWAIN) project is to determine if the West Antarctic ice sheet and its surrounding ice shelves collapsed during the Last Interglacial $(\sim 120000$ years before present). Chemicals, such as sodium, magnesium and calcium, that can originate from marine sources are of particular interest to this project because the levels of these components can be used to determine the proximity of an ice core drilling site to a marine environment in the past (Minikin and others, 1994; Guelle and others, 2001; Abram and others, 2013). It should be noted that these chemicals, particularly calcium, also have terrestrial sources (Abram and others, 2013). Therefore, comparison with sea-water sea-salt ratios and other techniques are required to partition aerosol records based on their sources. The ice core analyzed in this study was drilled at Skytrain Ice Rise during the 2018-19 Antarctic field season. If the West Antarctic ice sheet or the Filchner-Ronne Ice Shelf collapsed, then the levels of sea-salt aerosol deposited at Skytrain Ice Rise during the Last Interglacial would have been elevated relative to more recent warm periods because the site would have been closer to a marine environment. Secondarily, annual layer counts of sea-salt aerosol, particularly of sodium, could be used to date the shallower sections of the ice core. This project therefore requires reliable measurements of chemical species that can be used to infer the vicinity of the site to a marine environment and date the ice core.

Soluble ionic species are routinely measured in discrete ice core samples using ion chromatography (IC) (Legrand and others, 1984, 1993; Buck and others, 1992; Legrand and Mayewski, 1997; Littot and others, 2002). For these methods, discrete ice core meltwater samples are collected and individually analyzed. These efforts have produced valuable chemical records, such as those from the EPICA Dome C and South Pole (SP19) ice cores (Littot and others, 2002; Wolff and others, 2010; Winski and others, 2019). The depth resolution achieved using discrete samples depends on ice core sampling. This depth resolution can be as high as $1 \mathrm{~cm}$ (Winski and others, 2019), but sampling is labor-intensive and timeconsuming, particularly for deep ice cores, which require analysis of thousands of samples to produce high-resolution records.

Continuous flow analysis (CFA) techniques have been developed to reduce sample handling, decrease contamination, increase analysis speed and increase resolution of ice core measurements since the 1980s (Sigg and others, 1994; Röthlisberger and others, 2000; McConnell and others, 2002; Knüsel and others, 2003; Cole-Dai and others, 2006; Osterberg and others, 
2006; Kaufmann and others, 2008; Bigler and others, 2011). All CFA techniques involve a stand located in a freezer with a heated interface that is used to melt ice core segments lengthwise. The meltwater flows through a pump system directly to instruments for continuous measurements or to fraction collectors for subsequent discrete measurements.

Calcium ions, some of the first chemical components analyzed via CFA, were originally measured continuously using absorption spectroscopy (Sigg and others, 1994). The primary limitation of this method was spatial resolution, which was later overcome using fluorometric detection (Sigg and others, 1994; Röthlisberger and others, 2000).

Sodium was first continuously measured using an absorption spectrometric technique that required an enzymatic reaction online prior to the meltwater reaching the detector (Röthlisberger and others, 2000). Sodium and magnesium were first measured simultaneously using inductively coupled-plasma mass spectrometry (ICP-MS) (McConnell and others, 2002). The primary benefit of using ICP-MS was an improved depth resolution of $\sim 1 \mathrm{~cm}$ and simultaneous measurement of several elements by the same instrument (McConnell and others, 2002). Calcium has since also been measured concurrently with sodium and magnesium using ICP-MS and inductively coupled plasma time-of-flight mass spectrometry (ICP-TOF-MS) (Knüsel and others, 2003; Erhardt and others, 2019). Sodium, magnesium and calcium have also been measured continuously using IC and fast ion chromatography (FIC) methods. In FIC, meltwater is continuously pumped to a sample loop on an injection valve. The discrete volume of meltwater (i.e. sample) in the loop is then injected onto a column for separation at constant time intervals. These methods are therefore quasi-continuous. Quasi-continuous IC methods have the advantage of not requiring a reaction prior to sample introduction. As well as being suitable for anion analysis, they are also capable of analyzing several cations simultaneously, including those such as magnesium, which have not been measured via absorption or fluorescence spectroscopy. However, these continuous IC methods generally result in lower depth resolution than spectrometric techniques due to the relatively larger amount of meltwater required per analyzed sample (Huber and others, 2001; Cole-Dai and others, 2006; Morganti and others, 2007; Severi and others, 2015). To overcome this limitation, methods have been developed in which meltwater is continuously pumped to several ion chromatographs sequentially (Cole-Dai and others, 2006).

Unlike FIC methods, continuous ICP-MS techniques have the potential to detect the total elemental content (i.e. the dissolved and particulate fractions) of an analyte. Similar sodium and calcium concentrations, found when comparing continuous ICP-MS techniques to IC and spectroscopic methods, suggest that continuous ICP-MS methods are only capable of detecting dissolved analyte fractions (Knüsel and others, 2003; Erhardt and others, 2019). However, it is possible that the particulate fraction of an analyte is generally below detection, particularly in interglacial ice (Erhardt and others, 2019). For instance, Arienzo and others (2019) determined that their continuous ICP-MS method recovered $91-108,73-102$ and $54-78 \%$ of the sodium, magnesium and calcium levels detected in discrete samples using ICP-MS, respectively, depending on the ice core analyzed. Knüsel and others (2003) also found that their continuous ICP-MS method and their discrete inductively coupled plasma optical emission spectrometry (ICP-OES) method detected similar levels of magnesium and calcium.

Insoluble particles may be detected using continuous ICP-MS methods because they involve acidification of the meltwater online prior to sample introduction and vaporization of particles in the plasma (McConnell and others, 2002; Knüsel and others, 2003; Erhardt and others, 2019). However, unlike the acid digestion that samples are subjected to for discrete ICP-MS measurements, meltwater involved in CFA is acidified for a relatively shorter period of time $(<1 \mathrm{~min})$ before reaching the plasma (Knüsel and others, 2003; Ruth and others, 2008; Rhodes and others, 2011; Arienzo and others, 2019). Insoluble particles can also be lost at the melt interface or within the tubing that transports the meltwater, which would result in the detection of mostly the soluble fraction of the analyte (Knüsel and others, 2003). Detection of the particulate fraction of an analyte in ice core meltwater depends on the ICP-MS method employed and the ice core analyzed (Arienzo and others, 2019; Erhardt and others, 2019). These parameters emphasize the need to compare analyte concentrations detected using a continuous ICP-MS method to simultaneous continuous fluorescence and FIC measurements to determine if particulate fractions of the analytes of interest are detected using the ICP-MS technique. This comparison is crucial for scientific interpretation of the impurity records.

In this study, continuous ICP-MS and FIC methods for the analysis of sodium, magnesium and calcium are compared by directly flowing ice core meltwater to both systems simultaneously. Additionally, analysis of calcium using these methods is assessed relative to analysis of calcium using a continuous fluorescence spectroscopy method. Sodium, magnesium and calcium were chosen as analytes because they have both sea salt and dust sources (Fischer and others, 2007) and are commonly used for annual layer counting (Sigl and others, 2016; Winstrup and others, 2019; Winski and others, 2019). These concurrent measurements on the meltwater are advantageous because they do not require comparison of parallel pieces of ice core, which could be affected by horizontal heterogeneity. Erhardt and others (2019) compared simultaneous ICP-TOF-MS and spectroscopic methods to detect sodium and calcium. To our knowledge, this is the first study comparing continuous coincident FIC and ICP-MS measurements of sodium, magnesium and calcium from the same meltstream.

For application to the WACSWAIN project, the methods used in this study must be capable of detecting levels expected in the Skytrain ice core at the depth resolution needed for age scale development. Sodium is known to show distinct seasonal variations in many Antarctic ice cores and has proven to be a reliable marker for annual layer counting (Sigl and others, 2016). A goal of this project is to try to date the Skytrain ice core using annual layer counting of sodium for up to the last 2000 years. Magnesium and calcium levels could be used to confirm annual layers of sodium. Expected annual layer thickness for the last 2000 years is estimated to be $5-9 \mathrm{~cm}$ based on a modeled depth-age relationship at this site (personal communication from Carlos Martìn). Therefore, the depth resolution of sodium measurements needs to be high enough to enable clear annual cycle separation within a depth interval of at least $5 \mathrm{~cm}$. Annual cycle separation requires more than one measurement per year in order to resolve seasonal variability. Limits of detection also need to be below the minimum sodium, magnesium and calcium concentrations common in Antarctic ice cores of 5-10 $\mu \mathrm{g} \mathrm{L} \mathrm{L}{ }^{-1}, \quad 1 \mu \mathrm{g} \mathrm{L} \mathrm{L}^{-1}$ and $1-2 \mu \mathrm{g} \mathrm{L} \mathrm{L}^{-1}$, respectively (Röthlisberger and others, 2002; Sigl and others, 2016; Winski and others, 2019).

Therefore, in this study, a method comparison is used to determine (1) how the levels of the analytes vary between methods and (2) which method is the best choice for counting annual layers in the Skytrain ice core. For a better understanding of the context of this analysis, the Skytrain ice core drilling, transport, sampling and CFA methodology is also presented. 


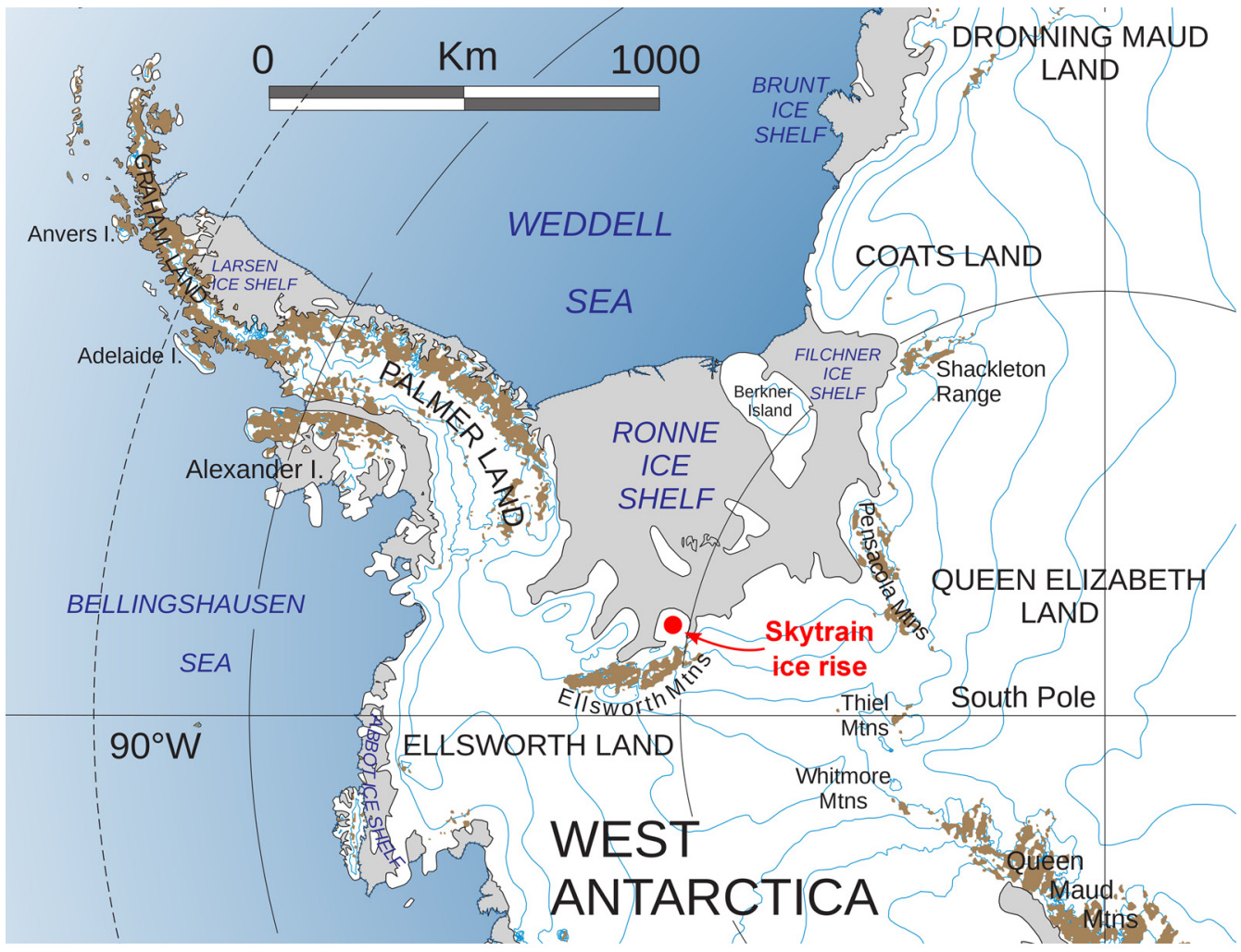

Fig. 1. Map of Skytrain Ice Rise ice core drilling site $\left(79^{\circ} 44.46^{\prime} \mathrm{S}, 78^{\circ} 32.69^{\prime} \mathrm{W}\right)$.

\section{Materials and methods}

\section{WACSWAIN ice core site characteristics}

The WACSWAIN ice core was drilled at Skytrain Ice Rise $\left(79^{\circ} 44.46^{\prime} \mathrm{S}, 78^{\circ} 32.69^{\prime} \mathrm{W}\right)$ at an altitude of $784 \mathrm{~m}$ above sea level (a.s.l.) $\sim 50 \mathrm{~km}$ north of the closest outcrop of the Ellsworth Mountains near the Ronne Ice Shelf during the 2018-19 Antarctic field season (Fig. 1). The basal topography of the site is $133 \mathrm{~m}$ a.s.l. with a mean annual surface temperature of $-26^{\circ} \mathrm{C}$. The ice core was drilled to the bed at a depth of 651 $\mathrm{m}$ (Mulvaney and others, 2021). Ice core samples analyzed in this study were from 295 to $305 \mathrm{~m}$ depth below the surface. This depth interval was mainly chosen because (1) it is well below the firn-ice transition, (2) the data produced by all of the methods at this interval was of high enough quality for statistical comparison and (3) the condition of the ice at this interval did not affect the resulting data.

\section{WACSWAIN ice core drilling, transport and storage}

The ice core was drilled using the British Antarctic Survey (BAS) deep drill (Mulvaney and others, 2007, 2021). After being extracted from the drill barrel, each ice core section was measured lengthwise and cut into $80 \mathrm{~cm}$ sections, using an electric cross-cut bench saw. For the first $291 \mathrm{~m}$, the weight and dimensions of each section were recorded to enable ice density to be calculated. Each $80 \mathrm{~cm}$ section was then stored in layflat polythene tubing. During the field season, sections of the ice core were stored in insulated boxes in a $3 \mathrm{~m}$ deep covered trench that was excavated in the snow. The ice core storage trench maintained a temperature generally below $-12^{\circ} \mathrm{C}$, with briefly warmer conditions (which would have been buffered within the insulated boxes) on occasions when the store entrance was open. The core was flown out of the site by a Twin Otter, typically within 1 or 2 weeks of the drilling. Most cores spent a period of a few days stored in an undersnow storage cave at the Sky Blu field station before being flown for storage to a cold store either at the Rothera Research Station or to the RRS Ernest Shackleton that was moored at the English Coast. They were loaded into a commercial reefer container at $-21^{\circ} \mathrm{C}$ and transported to the UK on the RRS Ernest Shackleton from January to April 2019. After reaching the UK, the ice core was stored in a commercial freezer storage facility at $-22^{\circ} \mathrm{C}$ until sample preparation.

\section{Ice core sample preparation}

Prior to cutting, the length of each $98 \mathrm{~mm}$ diameter section of the Skytrain Ice Rise ice core was remeasured. Breaks, wind crusts and other features apparent in the ice core sections were recorded. The solid conductivity of each section was calculated based on the dielectric properties of the ice measured using a custom-built dielectric profiling instrument (Wilhelms and others, 1998). The Skytrain Ice Rise ice core was then cut using a band saw into six lengthwise sections in the $-23^{\circ} \mathrm{C}$ cold room at BAS (Fig. 2). The core was first cut in half. One half of the core was preserved for future discrete total air content (TAC) and potentially for discrete trace gas measurements. The top of the other half of the core was then cut and stored for future laser ablation ICP-MS and potential physical properties measurements. Two sections at the outer part of this half core along its flat edge were cut and stored for discrete isotope measurements that could be used to supplement CFA isotope measurements in depth sections with poorer core quality. The inner portion of this half of the ice core was cut into two equally sized 3.2 $\mathrm{cm} \times 3.2 \mathrm{~cm} \times 80 \mathrm{~cm}$ sections. One of these sections was used for CFA. The sections of the ice core used for CFA were taken from the inner cross section of the cylindrical ice core to reduce contamination. All of the cut ice core sections were stored in a commercial freezer at $-20^{\circ} \mathrm{C}$ in plastic layflat bags in insulated boxes. Prior to analysis, the ends of each ice core section were 


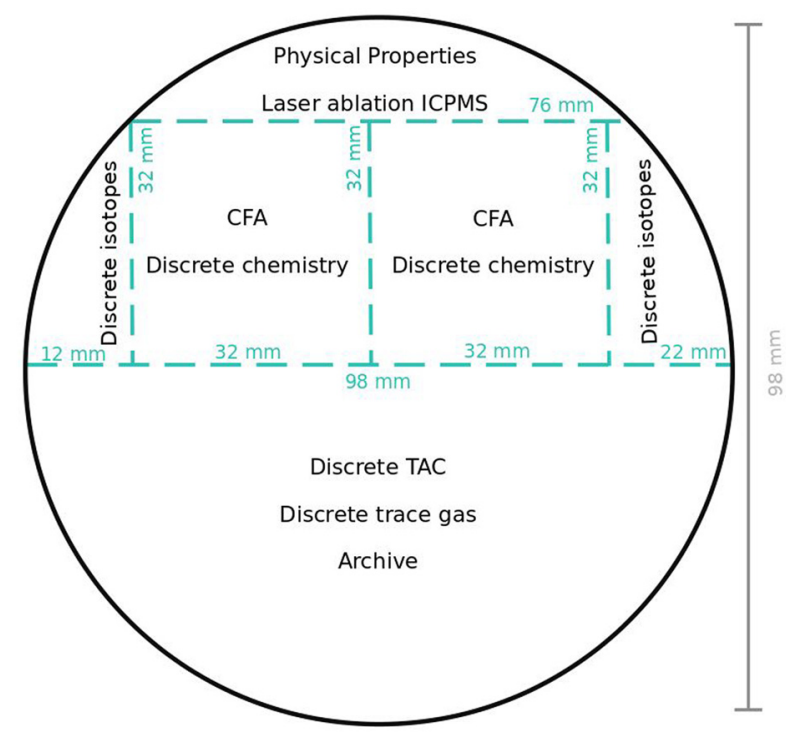

Fig. 2. Schematic of WACSWAIN ice core cross-sectional cutting plan. Dashed lines show lengthwise cuts.

shaved using a metal file to reduce contamination and then remeasured lengthwise in the cold room at BAS. Whenever the core material had to be touched directly, nitrile gloves were worn.

\section{Instrumentation}

The CFA system at BAS consists of a melting unit, a water and gas flow system and ten different sets of instrumentation for analyses (Fig. 3). This system has been used for previous ice core analyses and was improved, e.g. in terms of flow efficiency, for the WACSWAIN project. The instrumentation connected to the flow system consists of an Amber Science, Inc. 3082 series conductivity meter, a Dionex conductivity detector (CDM-1), an Abakus (Klotz) particle counter, three FIALab Precision Measurement Technologies photomultiplier tube fluorometers (PMT-FL), a Picarro L2130-i cavity ring down spectrometer (CRDS), a Picarro G2301 CRDS, an Agilent 7700x inductivelycoupled plasma mass spectrometer (ICP-MS), a Dionex ICS-6000 fast ion chromatography (FIC) system, a Dionex ICS-3000 FIC system and a bubble detector (Sonotec, Sonocheck ABD06.85). Each of these systems is used to analyze components that are relevant for understanding past atmospheric composition. Methods that employ the ICP-MS and FIC ICS-3000 systems to detect sodium, magnesium and calcium, along with the fluorometer for calcium detection, are the focus of this study.

The ice core melting unit consists of a Perspex ${ }^{\oplus}$ stand that is removed to load each $3.2 \mathrm{~cm} \times 3.2 \mathrm{~cm} \times 80 \mathrm{~cm}$ ice core section. The stand is then secured directly above the melt head. The melt head was designed, following Bigler and others (2011), with a copper base, due to its high thermal conductivity, on a $5 \mu \mathrm{m}$ layer of nickel with a $2 \mu \mathrm{m}$ gold surface coating. The interface has grooves that direct meltwater flow through a $1.6 \mathrm{~mm}$ diameter hole in its center. The melt head is heated using heating cartridges, which are controlled using a PID controller. The ice core melter and sample tubing were cleaned daily by wiping with lint-free tissues and sequentially flushing with isopropyl alcohol and ultrapure water.

The ice core melt rate is determined by the nominal temperature of the melt head, the density of the ice core and the gravitational load exerted on the core piece onto the melt head. The melt rate was kept at $\sim 3.0 \mathrm{~cm} \mathrm{~min}^{-1}$, mainly by adjusting the melt head temperature, to ensure a sufficient water supply for all instruments attached to the flow system. There are five meltwater streams. Meltwater from the inner section of the ice core is directed through a hole in the center of the melt head. This fraction of meltwater is the least contaminated of the ice core because it originates from the center of the ice core cross section. Only the meltwater created in that center section is then directed to all analytical instruments. The four other meltstreams originate from the outer sections of the ice core and are directed to waste or are collected for discrete analysis less prone to contamination.

Meltwater is directed through holes in the melt head into temperated PTFE (sample) and PFA (waste lines) tubing through the wall of the freezer. After exiting the freezer, meltwater from the inner section of the melt head flows through a non-invasive clip-on bubble detector (Sonotec, Sonocheck ABD06.85) used to measure the air to water ratio as a proxy for TAC (Kaufmann and others, 2008). All of the meltstreams then flow through an Ismatec ISM932D peristaltic pump (pump 1). The meltwater from the inner section of the ice core flows through the pump at $\sim 22 \mathrm{~mL} \mathrm{~min}^{-1}$. It is then pumped through a Vici EHMA valve followed by a custom-built gravity-controlled debubbler.

Meltwater containing air from the top of the debubbler flows through an Ismatec ISM930 peristaltic pump to the Picarro G2301 CRDS for $\mathrm{CH}_{4}$ analyses. Bubble-free meltwater flowing from the bottom of the debubbler is directed through the Ismatec ISM932D peristaltic pump a second time at a rate of 8 $\mathrm{mL} \mathrm{min}^{-1}$. This meltwater is then distributed to all of the other instruments using an Ismatec ISM934C peristaltic pump (pump 2). The whole flow system from the melt head up to peristaltic pump 2 has an internal volume of $\sim 3.85 \mathrm{~mL}$. From there, the lines going to the FIC, the ICP-MS and the fluorometer have volumes of $1.26,1.16$ and $0.11 \mathrm{~mL}$, respectively (Fig. 3). The spatial distances between the melt head and the instruments based on the length of tubing sum up to $9.1 \mathrm{~m}$ for the FIC, $7.1 \mathrm{~m}$ for the ICP-MS and $5.0 \mathrm{~m}$ for the fluorometer.

\section{Inductively-coupled plasma mass spectrometry}

An Agilent 7700x ICP-MS in no gas mode with argon carrier gas $\left(1.09 \mathrm{~L} \mathrm{~min}^{-1}\right)$ was used to measure elemental sodium (with a mass-to-charge ratio $\left(m z^{-1}\right)$ of 23$)$, magnesium $\left(24 m z^{-1}\right)$ and calcium isotopes (43 and $44 \mathrm{mz}^{-1}$ ). Meltwater was delivered to the system at a flow rate of $1.42 \mathrm{~mL} \mathrm{~min}{ }^{-1}$. A stream of $2 \%$ nitric acid at a flow rate of $0.1 \mathrm{~mL} \mathrm{m^{-1 }}$ was added to the meltwater flow online to improve sensitivity. This addition lowered the meltwater stream $\mathrm{pH}$ finally reaching the ICP-MS to $\sim 1.7$. The water was introduced into the instrument using a quartz nebulizer (Micromist) at an aspiration rate of $0.62 \mathrm{~mL} \mathrm{~min}^{-1}$ and a spray chamber that was water-cooled at $2^{\circ} \mathrm{C}$. The plasma was set with an RF forward power of $1550 \mathrm{~W}$. Measurements were taken with an integration time of $0.1 \mathrm{~s}$. Tuning parameters, including gas flows and ion optics, were adjusted daily using an Agilent tuning solution $\left(1 \mu \mathrm{g} \mathrm{L}^{-1} \mathrm{Ce}, \mathrm{Co}, \mathrm{Li}, \mathrm{Mg}, \mathrm{Tl}\right.$ and $\mathrm{Y}$ in $1 \mathrm{wt} \%$ $\mathrm{HNO}_{3}(\mathrm{aq})$ ) and a standard solution that was also used for calibration $\left(500 \mu \mathrm{g} \mathrm{L}^{-1} \mathrm{Na}\right.$ and $100 \mu \mathrm{g} \mathrm{L}^{-1} \mathrm{Mg}, \mathrm{Al}, \mathrm{Ca}, \mathrm{K}, \mathrm{NH}_{4}$, respectively, in $\left.1 \mathrm{wt} \% \mathrm{HNO}_{3}(\mathrm{aq})\right)$. The mass resolution achieved for sodium, magnesium, calcium-43 and calcium- 44 was on average $0.5 \mathrm{amu}$. Sensitivities of $\sim 20000$ counts per second (cps) per $\mu \mathrm{g}$ $\mathrm{L}^{-1}$ for sodium, $13000 \mathrm{cps}$ per $\mu \mathrm{g} \mathrm{\textrm {L } ^ { - 1 }}$ for magnesium and 30 cps per $\mu \mathrm{g} \mathrm{L}^{-1}$ for calcium-43 could be achieved.

\section{Fast ion chromatography}

A Dionex ICS-3000 FIC with conductivity detection was used to measure sodium, magnesium, calcium, ammonium and potassium ions. This experimental set-up consisted of two identical analytical systems. It therefore allowed for measurements at a better depth resolution relative to a traditional IC system because one 


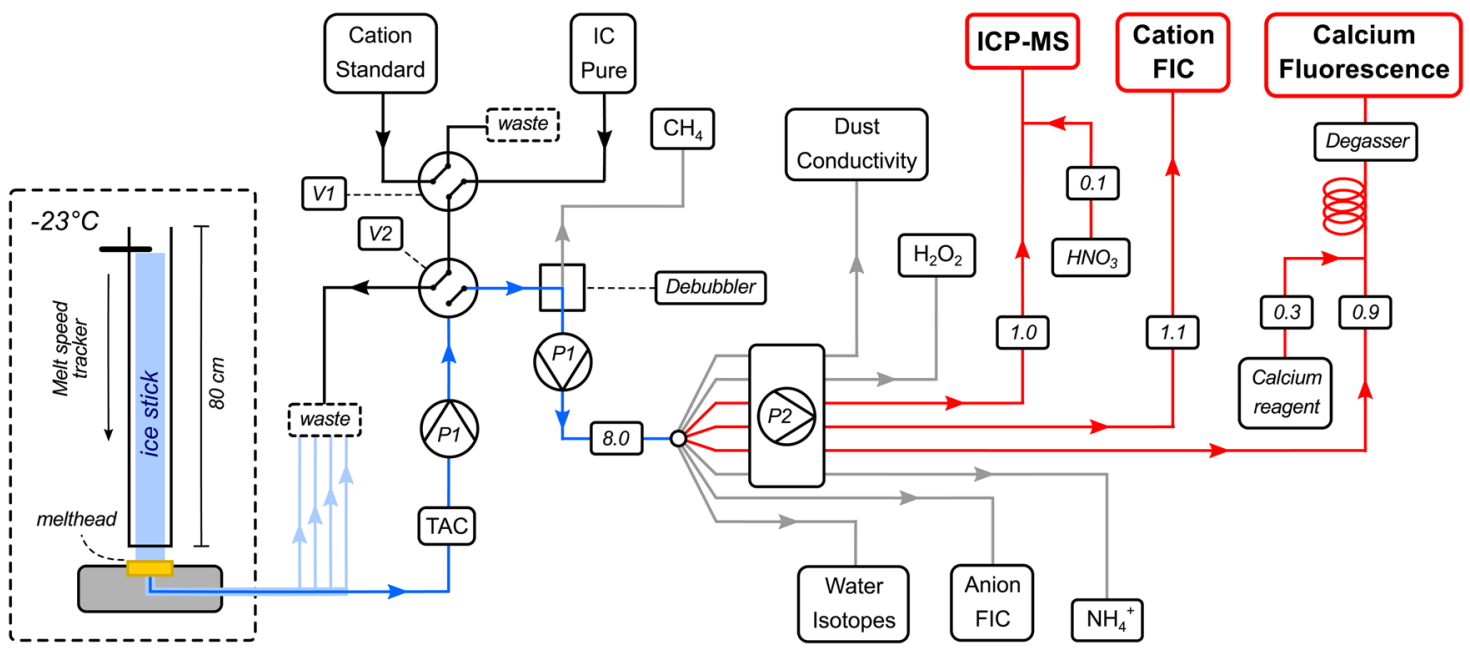

Fig. 3. Schematic of CFA system showing the melt system, pumps ( $p$ ), valves (v), standard introduction, ultrapure water introduction, reagent introduction, flow rates $\left(\mathrm{mL} \mathrm{min}^{-1}\right)$ and analytical systems in melting setup.

sample was already being loaded into the injection loop of one system while another was injected onto the column of the other system. For each analytical system, meltwater flowing from the melt head was loaded into a $1.0 \mathrm{~mL}$ injection loop at a flow rate only slightly above $1.0 \mathrm{~mL} \mathrm{~min} \mathrm{~min}^{-1}$ to ensure that the loop was filled completely. An automation manager valve built into the system allowed for automatic loading. Every $1.35 \mathrm{~min}$ the valve switched to load system 1 or 2 . Any excess meltwater was diverted to waste.

Each $1.0 \mathrm{~mL}$ sample was separated using a Dionex Ionpac CS12A $5 \mu \mathrm{m} 150 \mathrm{~mm}$ column and a $30 \mathrm{mM}$ methanesulfonic acid (MSA) eluent at a flow rate of $1.0 \mathrm{~mL} \mathrm{~min}^{-1}$. The eluent was generated electrolytically by an eluent generator cartridge (Dionex EGC III MSA). The CS12A column is designed for analyte separation with short retention times. A Dionex CERS 500e electrolytically regenerated suppressor was used to remove anions from the column effluent. The total run time for each sample was 2.7 min. In order to achieve this short run time for higher resolution measurements, calcium and magnesium ions from one sample injection were retained on the column and eluted on the following chromatogram. The retention times of sodium, ammonium and potassium were on average $2.2,2.4$ and $2.5 \mathrm{~min}$, respectively. The retention times for magnesium and calcium in the following run were 0.40 and $0.80 \mathrm{~min}$, respectively (Fig. 4).

\section{Fluorescence detection}

Fluorometry was employed as an additional method for calcium detection, using an FIAlab photomultiplier tube-fluorescence detector (PMT-FL). Ice core meltwater at a flow rate of $1.14 \mathrm{~mL}$ $\mathrm{min}^{-1}$ was combined online with a reagent at a flow rate of

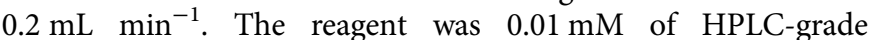
Quin-2 ( $\geq 99 \%$, Sigma-Aldrich) in a $35 \mathrm{mM}$ Suprapur sodium hydroxide solution (Merck) with a $20 \mathrm{mM}$ PIPES buffer $(\geq 95 \%$, Sigma-Aldrich). The mixture flowed through $0.8 \mathrm{~m}$ of coiled reaction tubing and a degasser (Systec, Multi Channel Vacuum Degasser) prior to introduction into the fluorometer, where it passed through a $15 \mathrm{~mm}$ long, $3 \mathrm{~mm}$ diameter, $100 \mu \mathrm{L}$ Suprasil flow cell with a $3 \mathrm{~mm}$ optical path length. An LED light with a band pass filter excites the fluorescent $\mathrm{Ca}^{2+}$ compound at $320 \pm 10 \mathrm{~nm}$. The PMT detects emission of the light after it passes through another band pass filter at $492 \pm 10 \mathrm{~nm}$.

\section{Standardization}

Intermediate standards were prepared using sodium (as $\mathrm{NaNO}_{3}$ in $2 \% \mathrm{HNO}_{3}, 1.000 \mathrm{mg} \mathrm{L} \mathrm{L}^{-1} \pm 0.005 \mathrm{mg} \mathrm{L}{ }^{-1}$, Sigma Aldrich),
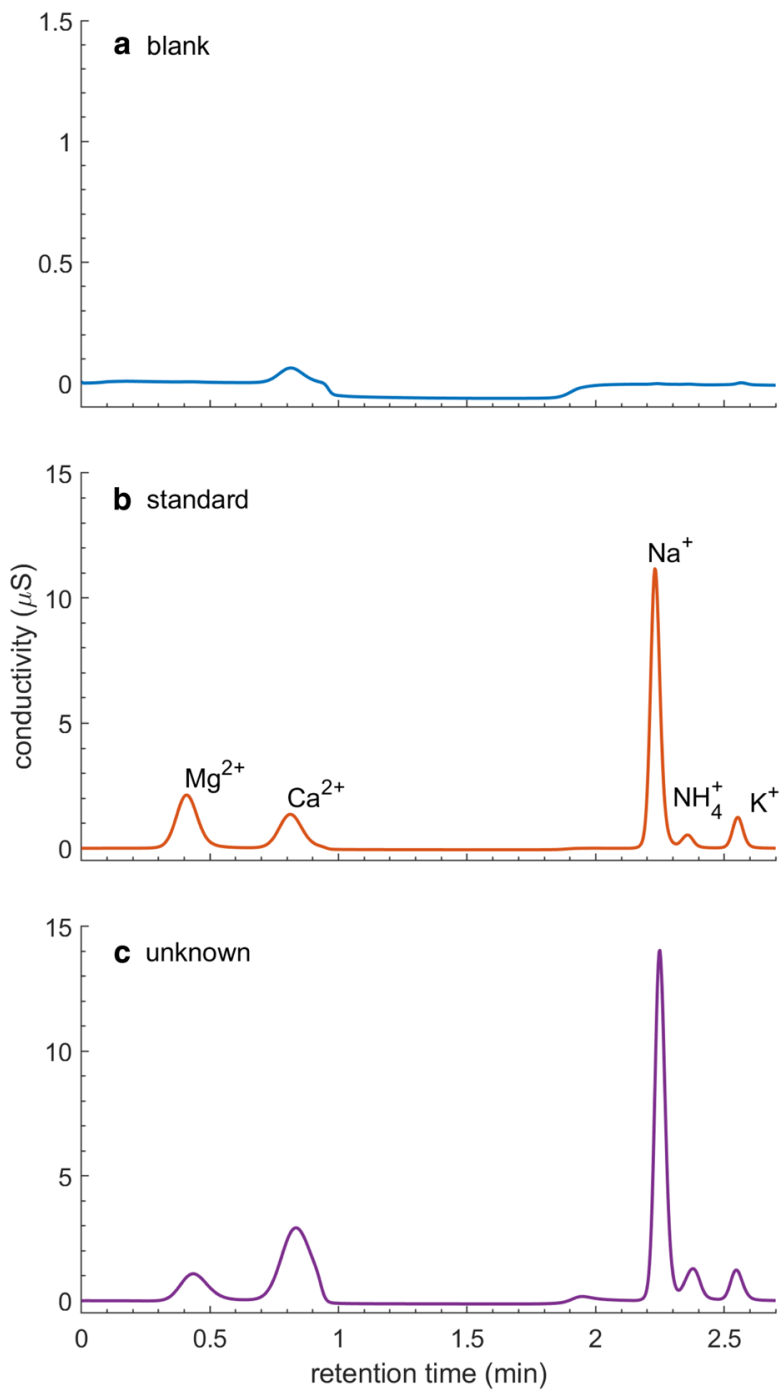

Fig. 4. Chromatograms produced using the FIC method: (a) ultrapure water blank, (b) standard (50 $\mu \mathrm{g} \mathrm{L}^{-1} \mathrm{Na}^{+}, 10 \mu \mathrm{g} \mathrm{L}^{-1} \mathrm{Ca}^{2+}, \mathrm{Mg}^{2+}, \mathrm{NH}_{4}^{+}$and $\left.\mathrm{K}^{+}\right)$and (c) a WACSWAIN ice core sample.

magnesium (as $\mathrm{Mg}\left(\mathrm{NO}_{3}\right)_{2}$ in $2 \% \mathrm{HNO}_{3}, 1006 \mathrm{mg} \mathrm{L}^{-1} \pm 4 \mathrm{mg} \mathrm{L}^{-1}$, Sigma Aldrich) and calcium (as $\mathrm{CaCO}_{3}$ in $2 \% \mathrm{HNO}_{3}$, $1000 \mathrm{mg} \mathrm{L}^{-1} \pm 2 \mathrm{mg} \mathrm{L}^{-1}$, Sigma Aldrich). The intermediate mixed standard was diluted to mixed solutions of $50 \mathrm{mg} \mathrm{L}^{-1}$ of sodium, $10 \mathrm{mg} \mathrm{L}^{-1}$ of magnesium and $10 \mathrm{mg} \mathrm{L}^{-1}$ of calcium in 
Table 1. ICP-MS, FIC and fluorescence method ice core concentration ranges and means, LODs, RSDs and percentages of measurements below LOD

\begin{tabular}{|c|c|c|c|c|c|c|c|c|}
\hline Method & Analyte(s) & $\begin{array}{l}\text { LOD } \\
\mu \mathrm{g} \mathrm{L}^{-1}\end{array}$ & $\begin{array}{l}\text { RSD } \\
\%\end{array}$ & $\begin{array}{l}\text { Range } \\
\mu \mathrm{g} \mathrm{L}^{-1}\end{array}$ & $\begin{array}{l}\text { Mean } \\
\mu \mathrm{g} \mathrm{L}^{-1}\end{array}$ & $\begin{array}{l}\text { below LOD } \\
\%\end{array}$ & $\begin{array}{l}n \\
\text { (blanks) } \\
(295-305 \mathrm{~m})\end{array}$ & $\begin{array}{l}n \\
\text { (standards) } \\
(295-305 \mathrm{~m})\end{array}$ \\
\hline ICP-MS & $\mathrm{Na}$ & 1.74 & 1.6 & $15-306$ & 55 & 0 & 55 & 54 \\
\hline FIC & $\mathrm{Na}^{+}$ & 1.34 & 6.1 & $12-311$ & 58 & 0 & 16 & 208 \\
\hline ICP-MS & Mg & 0.50 & 1.3 & $2.5-32$ & 7.4 & 0 & 54 & 54 \\
\hline FIC & $\mathrm{Mg}^{2+}$ & 0.41 & 9.3 & $2.6-25$ & 7.7 & 0 & 16 & 191 \\
\hline ICP-MS & ${ }^{43} \mathrm{Ca}$ & 0.38 & 1.2 & $0.50-28$ & 5.4 & 0 & 57 & 54 \\
\hline ICP-MS & ${ }^{44} \mathrm{Ca}$ & 0.88 & 1.5 & $<$ LOD to 25 & 4.2 & 4.2 & 55 & 47 \\
\hline FIC & $\mathrm{Ca}^{2+}$ & 1.09 & 10 & $1.61-30$ & 5.8 & 0 & 16 & 176 \\
\hline Flu. Det. & $\mathrm{Ca}^{2+}$ & 0.81 & 1.5 & $<$ LOD to 50 & 5.0 & 9.2 & 51 & 54 \\
\hline
\end{tabular}

The RSD is defined as the std dev. of concentrations of standards ( $10 \mu \mathrm{g} \mathrm{\textrm {L } ^ { - 1 }}$ for sodium and $2 \mu \mathrm{g} \mathrm{L}^{-1}$ for magnesium and calcium) divided by their known concentrations. The number of blank and standard measurements used for the RSD and LOD calculations are also listed (n). The best LOD and RSD values of the methods used are highlighted in bold.

ultrapure water. Working standards, ranging from 0 to $1000 \mu \mathrm{g}$ $\mathrm{L}^{-1}$ of sodium, 0 to $200 \mu \mathrm{g} \mathrm{L}^{-1}$ of magnesium and 0 to $200 \mu \mathrm{g}$ $\mathrm{L}^{-1}$ of calcium were prepared by dilution of these standards in ultrapure water monthly. All standards were refrigerated and shaken before use.

Calibration curves were produced daily over the range of the working standards for each method using a linear least squares regression. These curves were used to determine ice core sample concentrations. For FIC, the peak height was used for calibration. For the ICP-MS and fluorescence detection, the average level of the signal plateau after $\sim 5$ minutes of standard measurement was used for calibration. Standards were analyzed prior to ice core samples each day and after the end of ice core analysis each day.

\section{Results and discussion}

The methods utilized in this study were successfully used to detect sodium, magnesium and calcium in the Skytrain ice core. In this section, a segment of the Skytrain ice core from 295 to $305 \mathrm{~m}$ along with several standards and blanks are used to demonstrate the capability of the CFA system and compare the methods. The utility of each method for analysis of the Skytrain ice core is assessed based on its relative precision, limits of detection, depth resolution per measurement and measurement frequency. The physical states (i.e. soluble and insoluble fractions) of the chemical components detected using the ICP-MS method are then evaluated based on comparison to concentrations measured using the other methods at corresponding depths. Ratios of the levels of the analytes detected in this section of the ice core are also used to provide a preliminary interpretation of whether the species are of marine or terrestrial origin.

\section{Precision and limits of detection}

Given previously reported minimum Antarctic ice core concentrations (Röthlisberger and others, 2002; Sigl and others, 2016; Winski and others, 2019), we aimed for a precision of $\pm 0.5 \mu \mathrm{g} \mathrm{L}^{-1}$ for sodium and $\pm 0.1 \mu \mathrm{g} \mathrm{L}^{-1}$ for magnesium and calcium, or $\pm 5 \%$ of the lowest level standard used, which consisted of $10 \mu \mathrm{g} \mathrm{L}^{-1}$ of sodium and $2 \mu \mathrm{g} \mathrm{L}^{-1}$ of magnesium and calcium. In this study, the relative standard deviation (RSD) of the lowest level standard is used as a measure of precision. The RSD is defined as the std dev. of concentrations of the lowest level standards divided by their known levels after removal of outlier concentrations. The concentrations of the standards were calculated using their respective daily calibration curves. Outliers of the ICP-MS and fluorescence data were removed using the 'rmoutliers' Matlab function, in which values outside of the scaled median absolute deviation are removed. The RSD values of the ICP-MS and fluorescence methods for all of the compounds are below the 5\% goal and they are all lower than those of the FIC method (Table 1). This result suggests that, in terms of reproducibility of measurements at expected concentration levels, the ICP-MS and fluorescence methods are superior to the FIC method.

The limit of detection (LOD) is the lowest concentration of an analyte that can be reasonably measured using each method. We aimed to develop methods that reliably detect levels below minimum expected Antarctic ice core levels of sodium $\left(5 \mu \mathrm{g} \mathrm{L}^{-1}\right)$, magnesium $\left(1 \mu \mathrm{g} \mathrm{L}^{-1}\right)$ and calcium $\left(1 \mu \mathrm{g} \mathrm{L}^{-1}\right)$. In this study, the LOD is defined by

$$
\mathrm{LOD}=\mu_{b}+1.645\left(\sigma_{b}\right)+1.645\left(\sigma_{s}\right),
$$

where $\mu_{\mathrm{b}}$ is the mean of the blank concentrations, $\sigma_{\mathrm{b}}$ is the std dev. of the blank concentrations and $\sigma_{\mathrm{s}}$ is the std dev. of the lowest level standard concentrations $\left(10 \mu \mathrm{g} \mathrm{L}^{-1}\right.$ sodium, $2 \mu \mathrm{g} \mathrm{L}^{-1}$ magnesium and calcium) (Armbruster and Pry, 2008). The std dev. are multiplied by 1.645 in order to include the highest $95 \%$ of the measurements (assuming a Gaussian distribution).

The blank signal was determined by measuring ultrapure water $(R=18.2 \mathrm{M} \Omega \mathrm{cm})$ directly from the IC Pure system as sample. It therefore does not account for any contamination effects in the melt system before valve 2 (Fig. 3). Blank concentrations were determined using the instrument response of the blank and the daily calibration curves of the ICP-MS and fluorescence detection methods. For the FIC method, blank levels $(n=16)$ were determined using peak heights of ultrapure water and daily calibration curves from three days of analysis.

Differences in data collection and processing between the methods affect their respective LOD values. For sodium and magnesium, the LOD values of all three methods are well below minimum values observed between the Skytrain ice core depths of 295 and $305 \mathrm{~m}$. In terms of detection of low level concentrations, these methods are therefore acceptable for analysis of the Skytrain ice core. In general, the LODs for calcium are all well below mean levels of calcium in this depth interval. However, in some cases, the ICP-MS method for detection of calcium- 44 and the fluorescence method resulted in calcium values below their LODs in this section of the core (Table 1). The calcium methods are therefore generally sufficient for analysis of the Skytrain ice core, but it is worth noting that some observations were below detection.

\section{Depth resolution}

The depth resolution of each method is particularly important in ice core science because it determines the temporal resolution of the record produced. In this study, the aim was to develop methods that achieved depth resolutions at or below the modeled annual layer thickness of the Skytrain ice core at 2000 years before 


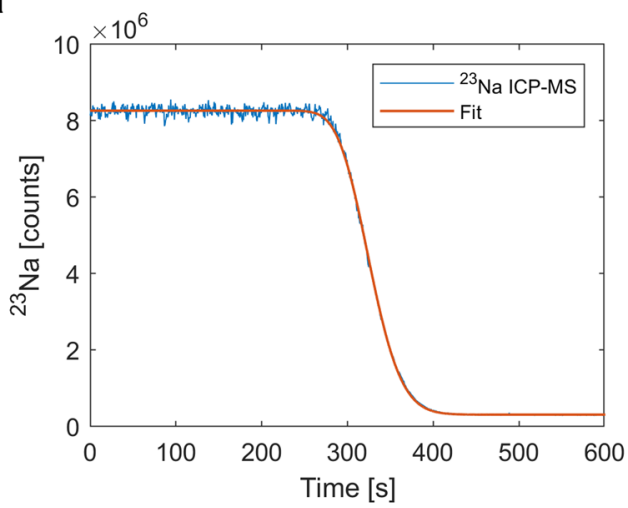

C

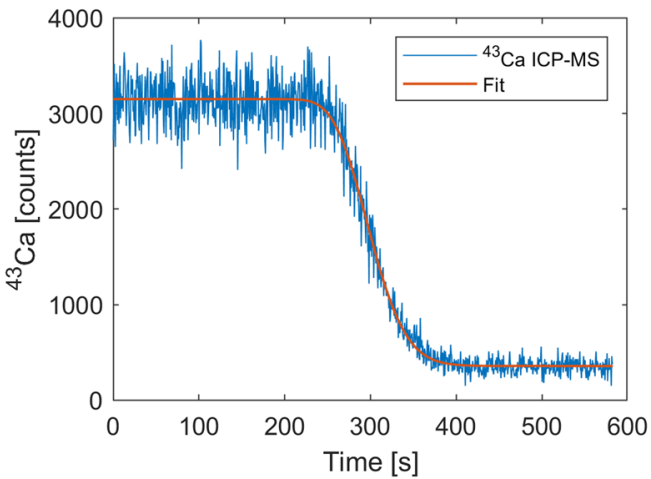

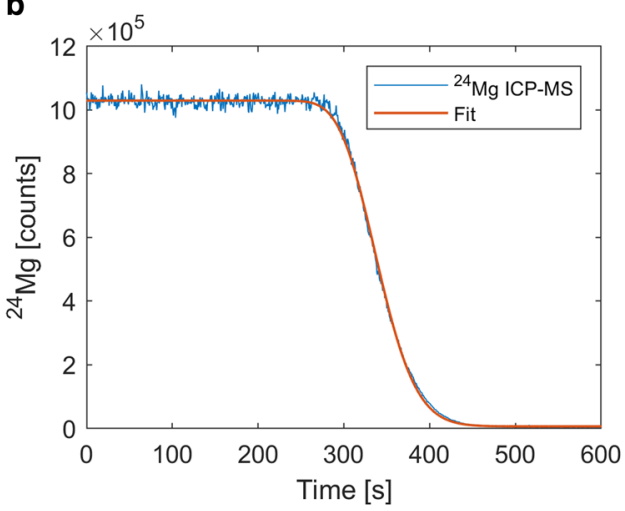

d

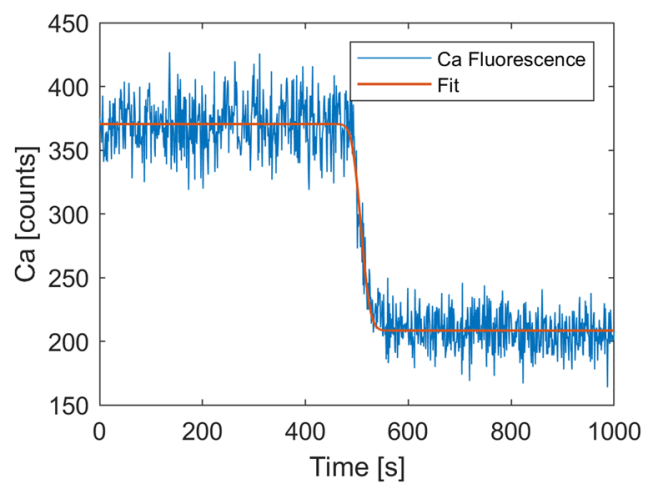

Fig. 5. Sodium (a), magnesium (b) and calcium (c, d) dispersion calculation for ICP-MS and fluorescence detection methods. Blue line shows decay of a standard (50 $\mu \mathrm{g} \mathrm{L}^{-1} \mathrm{Na}, 10 \mu \mathrm{g} \mathrm{L}^{-1} \mathrm{Mg}, \mathrm{Al}, \mathrm{Ca}, \mathrm{K}$ and $\mathrm{NH}_{4}$, respectively). Red line is the fit following Eqn (1) (Gkinis and others, 2010; Emanuelsson and others, 2015).

present $(\sim 5-9 \mathrm{~cm})$. Depth resolution is consistent throughout a measurement campaign at constant instrumental settings, but the temporal resolution decreases with depth because annual layer thickness decreases with depth. Depth resolution and the resulting temporal resolution of an ice core measurement depends on the sample injection rate, melt rate, flow rate and potential dispersion effects in the water lines as well as in the instruments. Depth resolution is determined by the mean difference in depth between each measurement. For continuous methods such as ICP-MS and fluorescence detection with very high sampling rates, the melt rate and the dispersion of the signal are the dominating and limiting factors (Sigg and others, 1994). To quantify this dispersion effect on depth resolution for the ICP-MS and the fluorescence detection systems, the response of the signal to a step change in concentration, namely a calibration standard, was evaluated. This was done following the procedure described in Gkinis and others (2010) and Emanuelsson and others (2015). Cumulative distribution functions of the lognormal distribution were fitted to the signal steps according to

$$
\delta_{f i t}(t)=\frac{a_{1}}{2}\left[1+\operatorname{erf}\left(\frac{\ln (t)-b}{c \sqrt{2}}\right)\right]+a_{2},
$$

where $t$ denotes the time and $\delta_{\text {fit }}(t)$ denotes the resulting fit function. The constants, $a_{1}, a_{2}, b$ and $c$, have been determined using a least squares optimization. Examples of the derived fit functions for all investigated analytes using a medium concentration standard $\left(50 \mu \mathrm{g} \mathrm{L}^{-1} \mathrm{Na}, 10 \mu \mathrm{g} \mathrm{L}^{-1} \mathrm{Mg}, \mathrm{Al}, \mathrm{Ca}, \mathrm{K}\right.$ and $\mathrm{NH}_{4}$, respectively) are shown in Figure 5. Subsequent to fitting, the time between the decrease from 90 to $10 \%$ of the average step height was evaluated in the fit function. This was done for ten different measurement days (30 samples) over the course of 3 months for the ICP-MS data and for 25 measurement days
Table 2. Decay times and resulting depth resolution for dispersion calculations for $\mathrm{Na}, \mathrm{Ca}$ and $\mathrm{Mg}$ in ICP-MS and fluorescence detection

\begin{tabular}{llll}
\hline Analyte & $n$ & $\begin{array}{c}\text { Decay time } \\
\mathrm{s}\end{array}$ & $\begin{array}{c}\text { Depth resolution } \\
\mathrm{cm}\end{array}$ \\
\hline${ }^{23} \mathrm{Na}$ ICP-MS & 30 & $76.0 \pm 8.3$ & $3.8 \pm 0.4$ \\
${ }^{24} \mathrm{Mg}$ ICP-MS & 30 & $94.3 \pm 7.6$ & $4.7 \pm 0.4$ \\
${ }^{43} \mathrm{Ca}$ ICP-MS & 30 & $86.2 \pm 15.9$ & $4.3 \pm 0.8$ \\
$\mathrm{Ca}^{2+}$ Flu. Det. & 70 & $26.7 \pm 9.9$ & $1.4 \pm 0.5$ \\
\hline
\end{tabular}

A melt rate of $3 \mathrm{~cm} \mathrm{~min}{ }^{-1}$ was used. $n$ denotes the number of evaluated samples. For the decay times, the median and STD was evaluated.

(70 samples) in the same time frame for the fluorescence detection method. Multiplication of the derived median decay times with the average melt rate $\left(3 \mathrm{~cm} \mathrm{~min}{ }^{-1}\right)$ yields the dispersion dominated depth resolution. An overview of the resulting values is given in Table 2 .

For the FIC method, this direct evaluation of a step in analyte concentration is not possible because each measurement is a discrete volume of meltwater injected from the sample loop. The depth interval in each injection volume can be calculated according to

$$
D_{\text {sample }}=\frac{V_{\text {sample }} R_{\text {melt }}}{R_{\text {flow }}}
$$

where $D_{\text {sample }}$ is the depth resolution of each sample injection, $V_{\text {sample }}$ is the sample loop volume $(1 \mathrm{~mL}), R_{\text {melt }}$ is the melt rate $\left(3 \mathrm{~cm} \mathrm{~min}^{-1}\right)$ and $R_{\text {flow }}$ is the flow rate $\left(1.14 \mathrm{~mL} \mathrm{~min}^{-1}\right)$ (Cole-Dai and others, 2006). Using this equation, the depth resolution of each FIC measurement is $2.63 \mathrm{~cm}$. However, each time meltwater flows through the sample loop, the loop is 'overfilled', meaning that some of the meltwater goes to waste. This is done 

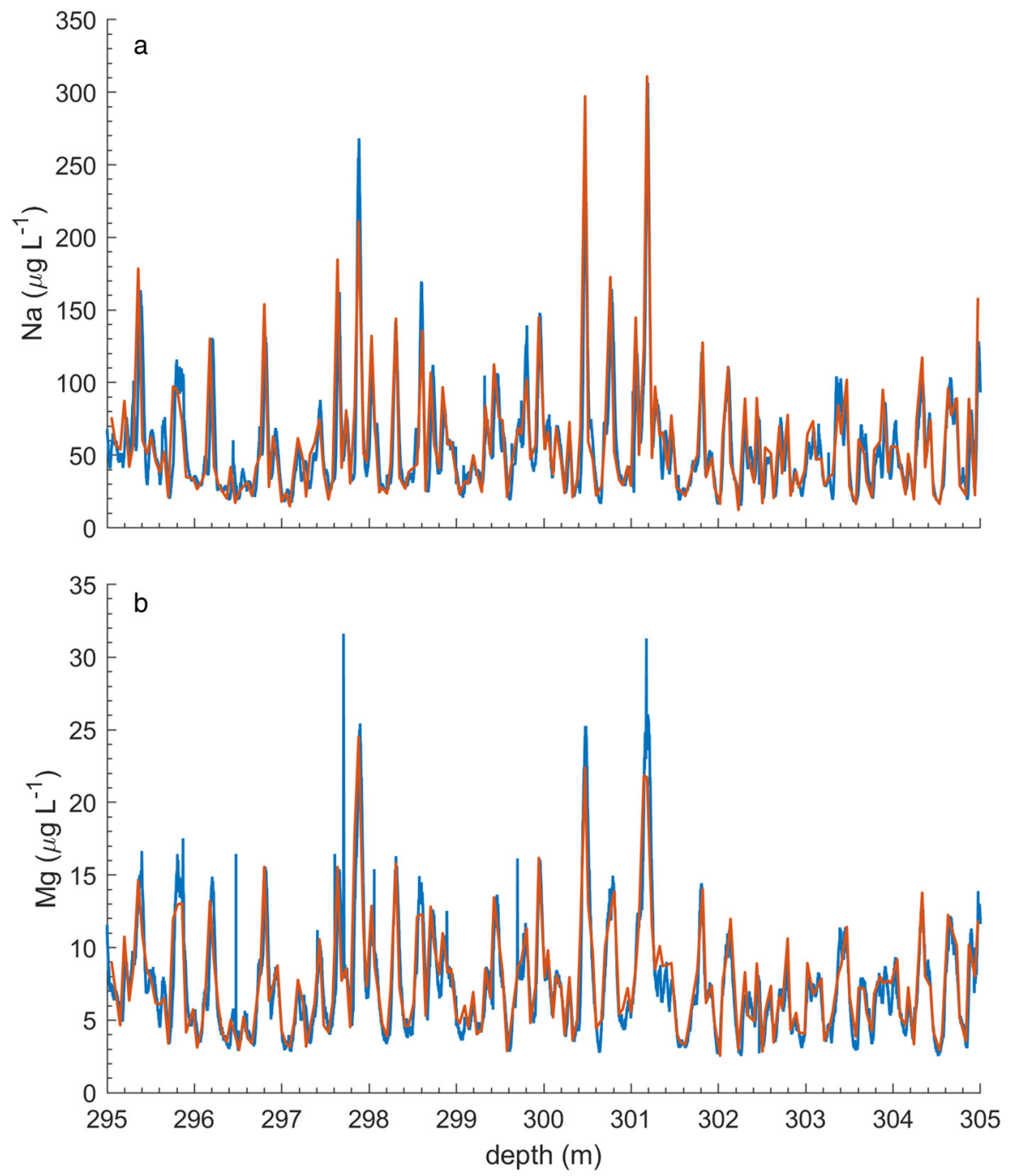

Fig. 6. Skytrain ice core: (a) sodium and (b) magnesium from 295 to $305 \mathrm{~m}$ depth. Measurements were made using ICP-MS (blue) and FIC (orange) methods.

to ensure that the sample loop does not contain any air or eluent prior to injection onto the column, which would affect the measurement. Due to this overfilling of the sample loop, some meltwater is lost between measurements. The depth interval lost between each FIC measurement can be calculated by

$$
D_{\text {loss }}=R_{\text {melt }} T-D_{\text {sample }},
$$

where $D_{\text {loss }}$ is the depth interval lost between FIC measurements and $T$ is the time interval over which the sample loop is filled (1.35 min) (Cole-Dai and others, 2006). This value can be interpreted as the time elapsed before the valve switches from system 1 to system 2 . This calculation results in a loss of $1.42 \mathrm{~cm}$ between FIC measurements ( $35 \%$ of the meltwater is lost). Therefore, there is one FIC measurement every $4.05 \mathrm{~cm}$. Consequently, the FIC method is only adequate for layer counting near the surface where annual layers span tens of centimeters (accumulation rate: $18 \mathrm{~cm}$ w.e. $\mathrm{a}^{-1}$ ) and for detection of peaks lasting several years (e.g. some volcanic eruptions). It is not suitable for annual layer counting at greater depths. If necessary for a future project, an improved depth resolution could be achieved by reducing the melt rate and flow rate to the FIC system within the limitations of the FIC system and parallel experimental systems.

An FIC depth resolution of $2.63 \mathrm{~cm}$ initially appears to be better than the $\sim 4 \mathrm{~cm}$ depth resolution calculated for the ICP-MS method (Table 2). However, it is important to note that the ICP-MS method has a measurement frequency equivalent to a depth interval of $0.04 \mathrm{~cm}$ (i.e. one $\sim 4-\mathrm{cm}$ sample every $0.04 \mathrm{~cm}$ ) compared to $4.05 \mathrm{~cm}$ for the FIC method (i.e. one $2.63-\mathrm{cm}$ sample every $4.05 \mathrm{~cm}$ ). There are therefore 101 ICP-MS measurements for every one FIC measurement. There are also 70 fluorescence measurements (i.e. one $1.4-\mathrm{cm}$ sample every $0.06 \mathrm{~cm}$ ) for every 1 FIC measurement. The ICP-MS method also samples meltwater more frequently than the fluorescence method for calcium, but the fluorescence method has $\sim 3 \times$ the depth resolution. This difference in depth resolution is caused by a larger dispersion of the signal in the ICP-MS measurement. This signal dispersion could be due to the proximity of the PMT-FL to the melter $(5.0 \mathrm{~m})$ relative to the ICP-MS $(7.1 \mathrm{~m})$ or differences in depth resolution produced within the instruments.

In essence, the ICP-MS and the fluorescence methods produce running averages at $\sim 4-\mathrm{cm}$ and $1.4-\mathrm{cm}$ depth resolutions, respectively, with no loss of sample between measurements. The advantage of these 'moving average' type data is that the ICP-MS and fluorescence methods are easily capable of resolving annual peaks that are $\sim 4 \mathrm{~cm}$ apart. They can therefore be used to count annual layers that are $5 \mathrm{~cm}$ thick. In contrast, the FIC method results in 'bin-averaged' type data at $4.05-\mathrm{cm}$ intervals that can only be used to identify annual signals where the accumulation rate is high and the ice core has not undergone thinning.

\section{Analyte recovery}

All of the methods in this study resulted in similar levels, ranges, and means from 295 to $305 \mathrm{~m}$ in the Skytrain ice core (Table 1). The variability of the levels of the compounds with depth was also 

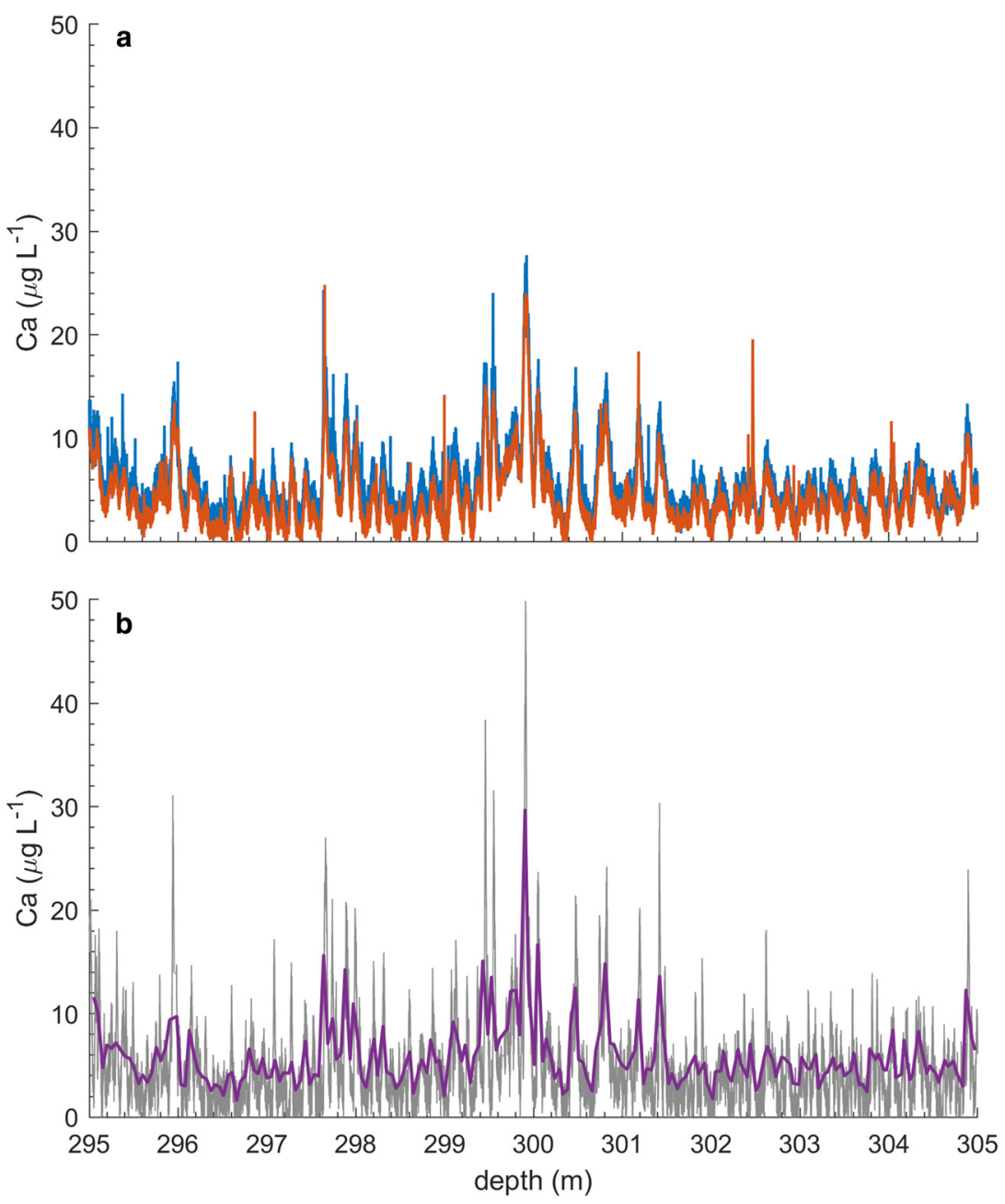

Fig. 7. Skytrain ice core calcium from 295 to $305 \mathrm{~m}$ depth: (a) calcium-43 (blue) and calcium-44 (orange) ICP-MS measurements; (b) calcium levels using the FIC method (violet) and fluorescence detection (gray).

similar for all of the methods (Figs 6, 7). A comparison between the concentrations detected using ICP-MS data from depths nearest to depths assigned to the FIC data resulted in slopes near 1 for all three elements with $r^{2}$ values above $0.76(n=204$; Fig. 8). The FIC method can only detect ions in solution. The similarity in analyte levels between the FIC and ICP-MS methods therefore suggests that the ICP-MS method also only detected soluble sodium, magnesium and calcium components. This result is in agreement with past studies that discuss the need to subject discrete samples to acid digestion in order to recover insoluble particles using ICP-MS (Knüsel and others, 2003; Ruth and others, 2008; Rhodes and others, 2011; Arienzo and others, 2019; Erhardt and others, 2019). This result is especially relevant for calcium which has significant soluble and insoluble terrestrial dust components (Ruth and others, 2008; Rhodes and others, 2011; Arienzo and others, 2019).

Prior to laboratory analysis, we calculated an expected sodium concentration deposited at the Skytrain Ice Rise site of $60 \mu \mathrm{g} \mathrm{L}^{-1}$. This value is based on the sea-water sodium/chloride ratio and the expected chloride concentration $550 \mathrm{~km}$ from the edge of the Ronne Ice Shelf, which is based on a $30 \%$ per 100 $\mathrm{km}$ reduction in concentration with distance from the coast reported in Minikin and others (1994). This $60 \mu \mathrm{g} \mathrm{L}^{-1}$ estimate is only slightly higher than mean sodium levels of $55 \mu \mathrm{g} \mathrm{L}^{-1}$ (ICP-MS) and $58 \mu^{-1} \mathrm{~L}^{-1}$ (FIC) in the Skytrain ice core from 295 to $305 \mathrm{~m}$ (Table 1). This analysis confirms that the Skytrain ice core sodium levels are consistent with the pattern observed in a previous study on the Ronne Ice Shelf, where the sodium concentration was indicative of distance from the ice edge (Miniken and others, 1994).

\section{Preliminary interpretation of sources}

A comprehensive climatic interpretation of the sodium, magnesium and calcium signals in the $10 \mathrm{~m}$ core section presented here is beyond the scope of this study, but we performed some initial analyses to explore possible interpretations of the records. Using the results of the ICP-MS method, the mean ratio of magnesium to sodium is 0.141 with a std dev. of $0.028(19.6 \%$ of the mean). This ratio is only slightly higher than the sea-water magnesium to sodium ratio of 0.119 , suggesting that most of the magnesium detected in this section of the ice core is likely of marine origin. The mean ratio of calcium (ICP-MS calcium-43) to sodium of 0.112 is substantially higher than the sea-water calcium to sodium ratio of 0.038 . However, with a std dev. of $0.063(56 \%$ of the mean), this ratio is three times as variable as the magnesium to sodium ratio and ratios of calcium to sodium range from 0.0165 to 0.562 along this depth interval. Variability of sodium levels and ratios of calcium to sodium are also strongly out of phase along the depth scale. These findings suggest a periodic shift in the sources of calcium to the ice core site, which needs to be investigated further.

\section{Conclusion}

The methods used in this study for analysis of the Skytrain ice core are assessed based on expected analyte levels in an Antarctic ice core and the $5 \mathrm{~cm}$ depth resolution needed to date the ice core using annual layer counting to 2000 years before present. In general, the ICP-MS and fluorescence detection (for calcium analysis) methods out-perform the FIC method. These methods have 

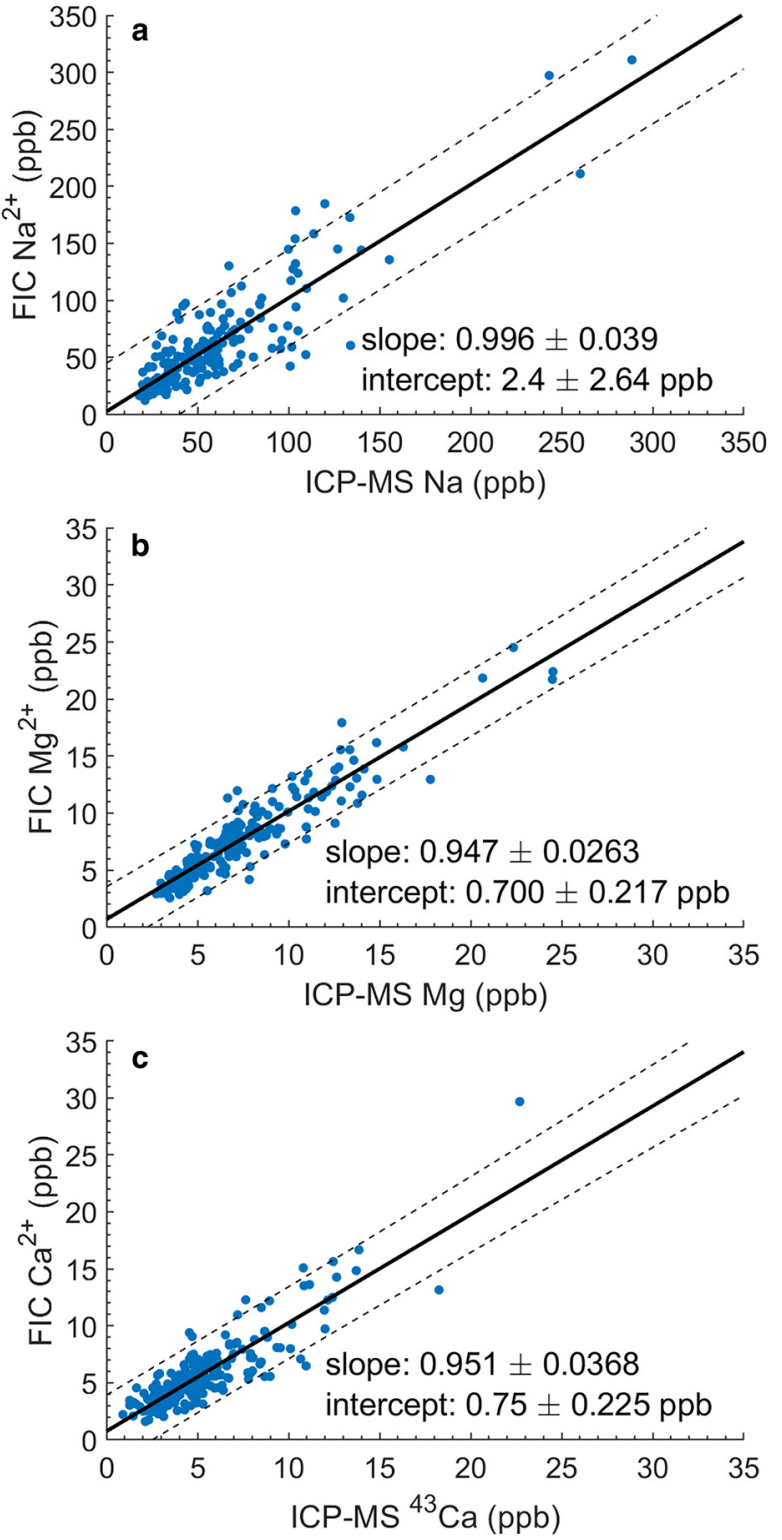

Fig. 8. Skytrain ice core ICP-MS and FIC method comparison. Points are (a) sodium, (b) magnesium or (c) calcium (one example) levels using each method from 295 to $305 \mathrm{~m}(n=204)$. Points for the ICP-MS method are ICP-MS data at depths nearest to depths assigned to the FIC data. Solid line is the linear fit $\left(R^{2}=0.76\right.$ for $\mathrm{Na}$, $R^{2}=0.87$ for $\mathrm{Mg}$ and $R^{2}=0.77$ for $\mathrm{Ca}$ ). Dashed line is the standard error of the fit.

relatively higher precision and measurement frequency. Although the ICP-MS method is generally better for analysis of the Skytrain ice core, comparison to the FIC method is useful for determining if the ICP-MS method is capable of detecting insoluble sodium, magnesium or calcium particles. The statistically similar analyte levels between all of the methods from 295 to 305 m suggest that the ICP-MS method only detects the soluble fraction of the analytes. All of the methods will be used to complete this comparison for the whole of the Skytrain ice core. The fluorescence method is a particularly useful comparison to the ICP-MS method because it produces soluble calcium data at a high depth resolution.

The depth resolution of most of the methods used in this study is $\sim 4 \mathrm{~cm}$ at a melt rate of $3 \mathrm{~cm} \mathrm{~min}^{-1}$. This is a low depth resolution relative to other CFA systems (McConnell and others, 2002; Cole-Dai and others, 2006; Bigler and others, 2011). However, the ICP-MS and the calcium fluorescence methods are capable of resolving annual layers of sodium, magnesium and calcium from the top of the Skytrain ice core to $\sim 250 \mathrm{~m}$, which is the depth modeled to reach 2000 years before present. These methods are therefore sufficient for the purposes of the WACSWAIN project. The depth interval of each FIC measurement $(4.05 \mathrm{~cm})$ is too wide to identify annual layers in the deeper sections of the Skytrain ice core. Reducing the melt rate could improve this measurement frequency. However, it is currently not possible to reduce the melt rate below $\sim 2.5 \mathrm{~cm} \mathrm{~min}^{-1}$ if meltwater is distributed to all of the instruments coupled to the BAS CFA system.

Annual layers were not expected to be visible within the depth interval presented in this study, from 295 to $305 \mathrm{~m}$, because the modeled depth-age relationship produces an annual layer thickness of $\sim 3 \mathrm{~cm} \mathrm{a}^{-1}$ at this depth interval. Only the calcium fluorescence method, with a relatively high depth resolution of $\sim 1.4 \mathrm{~cm}$, has the potential to resolve annual signals at this depth. Additionally, the depth-age relationship derived from attempted annual layer counting of ICP-MS sodium measurements no longer follows its expected exponential decline and becomes linear between 250 and $300 \mathrm{~m}$. This finding supports the conclusion that annual layers could not be resolved from 295 to $305 \mathrm{~m}$. It also strongly indicates that the resolution of the instruments prohibits separation of annual peaks below $250 \mathrm{~m}$.

All of the methods presented in this study could be improved for future analyses. For instance, shorter lengths of tubing between the melt head and the instruments would improve depth resolution by reducing dispersion of the signal. Decreasing the melt rate would also improve depth resolution, but the ability to reduce the melt rate is dependent on the total volume of meltwater required for all of the instruments connected to the CFA system.

One of the major limitations of the FIC method is that only one measurement is made every $\sim 4 \mathrm{~cm}$. This depth interval per measurement could be improved if less meltwater is lost between measurements, which could be achieved by decreasing the meltwater flow rate to the FIC. The addition of more FIC instruments sequentially measuring meltwater would also improve the depth resolution of the FIC method (Cole-Dai and others, 2006). However, this addition would require a higher volume of meltwater diverted to the FIC systems, which would limit meltwater available for other measurements. A better assessment of the effect of dispersion of the FIC signal could also be achieved by the addition of a conductivity sensor at the inlet of the sample loop.

Two major advantages of the BAS CFA system are that it is capable of measuring (1) several different chemical species and (2) the same chemical species using two to three different methods. All of these measurements are simultaneous on the same piece of ice. The weaknesses of each analytical system can therefore be compensated by the strengths of another system, which allows for a more comprehensive understanding of the underlying ice core signal. The disadvantage of the BAS CFA system is that the quality of a particular measurement must sometimes be compromised to balance the requirements of all of the instruments. However, the versatility of the BAS system allows for optimization of particular measurements when necessary by removal of individual instruments.

Acknowledgements. The authors thank Shaun Miller, Isobel Rowell, Amy King, Emily Ludlow and Victoria Alcock for help with cutting and processing the ice core. The authors also thank Charlie Durman and Isobel Rowell for ice core preparation for the CFA. This project has received funding from the European Research Council under the Horizon 2020 research and innovation program (grant agreement No. 742224, WACSWAIN). This material reflects only the author's views and the Commission is not liable for any use that may be made of the information contained therein.

\section{References}

Abram NJ, Wolff EW and Curran MA (2013) A review of sea ice proxy information from polar ice cores. Quaternary Science Reviews 79, 168-183. doi: 10.1016/j.quascirev.2013.01.011. 
Arienzo MM, McConnell JR, Chellman N and Kipfstuhl S (2019) Method for correcting continuous ice-core elemental measurements for underrecovery. Environmental Science \& Technology 53(10), 5887-5894. doi: 10.1021/acs.est.9b00199.

Armbruster DA and Pry T (2008) Limit of blank, limit of detection and limit of quantitation. The Clinical Biochemist Reviews 29(suppl. 1), S49. (pmid: 18852857).

Bigler M and 5 others (2011) Optimization of high-resolution continuous flow analysis for transient climate signals in ice cores. Environmental Science \& Technology 45(10), 4483-4489. doi: 10.1021/es200118j.

Buck C and 5 others (1992) Determination of major ions in snow and ice cores by ion chromatography. Journal of Chromatography A 594(1-2), 225-228. doi: 10.1016/0021-9673(92)80334-Q

Cole-Dai J, Budner DM and Ferris DG (2006) High speed, high resolution, and continuous chemical analysis of ice cores using a melter and ion chromatography. Environmental Science \& Technology 40(21), 6764-6769. doi: 10.1021/es061188a.

Emanuelsson BD, Baisden WT, Bertler NAN, Keller ED and Gkinis V (2015) High-resolution continuous-flow analysis setup for water isotopic measurement from ice cores using laser spectroscopy. Atmospheric Measurement Techniques 8(7), 2869-2883. doi: 10.5194/ amt-8-2869-2015.

Erhardt T, Jensen CM, Borovinskaya $O$ and Fischer H (2019) Single particle characterization and total elemental concentration measurements in polar ice using continuous flow analysisinductively coupled plasma time-of-flight mass spectrometry. Environmental Science \& Technology 53(22), 13275-13283. doi: 10.1021/ acs.est.9b03886.

Fischer H, Siggaard-Andersen ML, Ruth U, Röthlisberger R and Wolff E (2007) Glacial/interglacial changes in mineral dust and sea-salt records in polar ice cores: sources, transport, and deposition. Reviews of Geophysics 45(1), RG1002. doi: 10.1029/2005RG000192.

Gkinis V, Popp TJ, Johnsen SJ and Blunier T (2010) A continuous stream flash evaporator for the calibration of an IR cavity ring-down spectrometer for the isotopic analysis of water. Isotopes in Environmental and Health Studies 46(4), 463-475. doi: 10.1080/ 10256016.2010.538052.

Guelle W, Schulz M, Balkanski Y and Dentener F (2001) Influence of the source formulation on modeling the atmospheric global distribution of sea salt aerosol. Journal of Geophysical Research: Atmospheres 106(D21), 27509-27524. doi: 10.1029/2001JD900249.

Huber TM, Schwikowski M and Gäggeler HW (2001) Continuous melting and ion chromatographic analyses of ice cores. Journal of Chromatography A 920(1-2), 193-200. doi: 10.1016/S0021-9673(01)00613-6.

Kaufmann PR and 7 others (2008) An improved continuous flow analysis system for high-resolution field measurements on ice cores. Environmental Science \& Technology 42(21), 8044-8050. doi: 10.1021/es8007722.

Knüsel S, Piguet DE, Schwikowski M and Gäggeler HW (2003) Accuracy of continuous ice-core trace-element analysis by inductively coupled plasma sector field mass spectrometry. Environmental Science \& Technology 37(10), 2267-2273. doi: 10.1021/es026452o.

Legrand M, De Angelis M and Delmas R (1984) Ion chromatographic determination of common ions at ultratrace levels in Antarctic snow and ice. Analytica Chimica Acta 156, 181-192. doi: 10.1016/S0003-2670(00) 85549-X.

Legrand M, De Angelis M and Maupetit F (1993) Field investigation of major and minor ions along summit (Central Greenland) ice cores by ion chromatography. Journal of Chromatography A 640(1-2), 251-258. doi: 10.1016/ 0021-9673(93)80188-E.

Legrand M and Mayewski P (1997) Glaciochemistry of polar ice cores: a review. Reviews of Geophysics 35(3), 219-243. doi: 10.1029/96RG03527.
Littot GC and 9 others (2002) Comparison of analytical methods used for measuring major ions in the EPICA Dome C (Antarctica) ice core. Annals of Glaciology 35, 299-305. doi: 10.3189/172756402781817022.

McConnell JR, Lamorey GW, Lambert SW and Taylor KC (2002) Continuous ice-core chemical analyses using inductively coupled plasma mass spectrometry. Environmental Science \& Technology 36(1), 7-11. doi: 10.1021/es011088z.

Minikin A, Wagenbach D, Graf W and Kipfstuhl J (1994) Spatial and seasonal variations of the snow chemistry at the central Filchner-Ronne ice shelf, Antarctica. Annals of Glaciology 20, 283-290. doi: 10.3189/ 1994AoG20-1-283-290.

Morganti A and 5 others (2007) An improved flow analysis-ion chromatography method for determination of cationic and anionic species at trace levels in Antarctic ice cores. Analytica Chimica Acta 603(2), 190-198. doi: 10.1016/j.aca.2007.09.050.

Mulvaney R and 8 others (2021) Ice drilling on Skytrain Ice Rise and Sherman Island, Antarctica. Annals of Glaciology 62, 1-13. doi: 10.1017/aog.2021.7.

Mulvaney R, Alemany $\mathbf{O}$ and Possenti P (2007) The Berkner Island (Antarctica) ice-core drilling project. Annals of Glaciology 47, 115-124. doi: $10.3189 / 172756407786857758$.

Osterberg EC, Handley MJ, Sneed SB, Mayewski PA and Kreutz KJ (2006) Continuous ice core melter system with discrete sampling for major ion, trace element, and stable isotope analyses. Environmental Science \& Technology 40(10), 3355-3361. doi: 10.1021/es052536w.

Rhodes RH, Baker JA, Millet MA and Bertler NA (2011) Experimental investigation of the effects of mineral dust on the reproducibility and accuracy of ice core trace element analyses. Chemical Geology 286(3-4), 207-221. doi: 10.1016/j.chemgeo.2011.05.006.

Röthlisberger R and 6 others (2000) Technique for continuous high-resolution analysis of trace substances in firn and ice cores. Environmental Science \& Technology 34(2), 338-342. doi: 10.1021/es9907055.

Röthlisberger R and 6 others (2002) Dust and sea salt variability in central East Antarctica (Dome C) over the last 45 kyrs and its implications for southern high-latitude climate. Geophysical Research Letters 29(20), 1963. doi: 10.1029/2002GL015186.

Ruth U and 9 others (2008) Proxies and measurement techniques for mineral dust in Antarctic ice cores. Environmental Science \& Technology 42(15), 5675-5681. doi: 10.1021/es703078z.

Severi M, Becagli S, Traversi R and Udisti R (2015) Recovering paleo-records from Antarctic ice-cores by coupling a continuous melting device and fast ion chromatography. Analytical Chemistry 87(22), 11441-11447. doi: 10. 1021/acs.analchem.5b02961.

Sigg A, Fuhrer K, Anklin M, Staffelbach T and Zurmuehle D (1994) A continuous analysis technique for trace species in ice cores. Environmental Science \& Technology 28(2), 204-209. doi: 10.1021/es00051a004.

Sigl M and 26 others (2016) The WAIS Divide deep ice core WD2014 chronology - part 2: annual-layer counting (0-31 ka bp). Climate of the Past 12(3), 769-786. doi: 10.5194/cp-12-769-2016.

Wilhelms F, Kipfstuhl J, Miller H, Heinloth K and Firestone J (1998) Precise dielectric profiling of ice cores: a new device with improved guarding and its theory. Journal of Glaciology 44(146), 171-174. doi: 10.3189/ S002214300000246X.

Winski DA and 30 others (2019) The SP19 chronology for the South Pole Ice Core - part 1: volcanic matching and annual layer counting. Climate of the Past 15(5), 1793-1808. doi: 10.5194/cp-15-1793-2019.

Winstrup M and 26 others (2019) A 2700-year annual timescale and accumulation history for an ice core from Roosevelt Island, West Antarctica. Climate of the Past 15(2), 751-779. doi: 10.5194/cp-15-751-2019.

Wolff E and 29 others (2010) Changes in environment over the last 800000 years from chemical analysis of the EPICA Dome C ice core. Quaternary Science Reviews 29(1-2), 285-295. doi: 10.1016/j.quascirev.2009.06.013. 